\title{
Patient-Reported Outcomes/Satisfaction and Spectacle Independence with Blended or Bilateral Multifocal Intraocular Lenses in Cataract Surgery
}

This article was published in the following Dove Press journal: Clinical Ophthalmology

\author{
John A Hovanesian' \\ Stephen S Lane ${ }^{2}$ \\ Quentin B Allen ${ }^{3}$ \\ Michael Jones ${ }^{4}$ \\ 'Harvard Eye Associates, Laguna Hills, \\ CA, USA; ${ }^{2}$ Associated Eye Care, \\ Stillwater, MN, USA; ${ }^{3}$ Florida Vision \\ Institute, Stuart, FL, USA; ${ }^{4}$ Quantum \\ Vision Centers, Swansea, IL, USA
}

Correspondence: John A Hovanesian Harvard Eye Associates, 2440I Calle De La Louisa, Laguna Hills, CA 92653, USA Tel + I 949 95। 2020

Fax + I 949 95। 9244

Email jhovanesian@harvardeye.com
Purpose: To compare patient-reported outcomes (PROs) and satisfaction results after multifocal intraocular lens (IOL) implantation in three groups: two receiving bilateral implantation of the same IOL and another undergoing blended vision with two different multifocal IOLs. Patients and methods: A questionnaire was administered to patients who had undergone uncomplicated cataract surgery and 2 months of follow-up: the first group underwent bilateral implantation with Alcon's AcrySof ReSTOR 3.0 lens ("3.0/3.0," n=78); the second group underwent implantation with the ReSTOR ActiveFocus 2.5 or the ReSTOR ActiveFocus 2.5 toric lens (" 2.5 mini-monovision," $\mathrm{n}=102$ ); and the third group underwent implantation with the ReSTOR 2.5 lens in the dominant eye and the ReSTOR 3.0 lens in the non-dominant eye ("2.5/3.0," n=89).

Results: Overall PROs and satisfaction was similar among the groups. Refractive outcomes and accuracy were similar among the groups, but the 2.5 mini-monovision group reported better intermediate vision. Refractive outcome differences were not meaningful among the groups and were not a differentiating factor in PROs. Substantially fewer patients in the 2.5 mini-monovision group noticed glare and halo compared with the 3.0/3.0 group $(P<0.0001$, chi-square test). No new safety concerns were reported.

Conclusion: The 2.5 mini-monovision results in a higher percentage of patients being satisfied with intermediate vision than bilateral ReSTOR 3.0 or blended vision with ReSTOR 2.5/3.0 implants, but overall PRO differences were not statistically significant.

Keywords: mini-monovision, AcrySof ReSTOR, cataract surgery, spectacle independence, glare, multifocal intraocular lens

\section{Introduction}

Cataract extraction and intraocular lens (IOL) implantation is currently the most common surgical procedure performed in the United States; ${ }^{1}$ cataract affects upwards of 22 million Americans. ${ }^{2}$ Both the safety and efficacy of the procedure are well established, as is the improvement in overall quality of life. . $^{1,3}$

The commercial introduction of devices such as smartphones, tablets, and laptop computers has driven patient demands for spectacle independence across all ranges of distance, not just the traditional distance vision. In response, today's cataract surgery is often equal parts refractive procedure and vision restoration, and various IOLs have been introduced to address patient demands. Multifocal IOLs have been found to provide patients with better overall visual acuity (VA) in intermediate and distance and greater spectacle independence at near than monofocal IOLs, ${ }^{4,5}$ even 
when reports of glare are higher in a multifocal IOL group. ${ }^{4}$ Multifocal IOLs are also considered cost-effective for patients who want a better chance at being spectaclefree. ${ }^{6}$ Cochener et $\mathrm{al}^{7}$ conducted a meta-analysis on the clinical outcomes of different multifocal IOLs and found an apodized, diffractive IOL (AcrySof ${ }^{\circledR}$ IQ ReSTOR ${ }^{\circledR}$; Alcon Laboratories, Inc., Fort Worth, TX, USA) produced better uncorrected distance and near VA (UCDVA and UCNVA, respectively) than others, but did not comment on intermediate vision. Diffractive IOLs have a reported 1.75 times greater likelihood of spectacle independence than other multifocal IOLs. ${ }^{5}$ In their meta-analysis, Cao et al found multifocal lenses provided better near and intermediate vision (both corrected and uncorrected). ${ }^{8}$ However, patient-reported outcomes (PROs) have suggested more frequent dysphotopsia and worse contrast sensitivity, especially with low light or glare, with multifocal IOLs than with monofocal lenses. ${ }^{4,8-13}$ Glare and halo, caused by the transition zone between the diffractive steps, have been reported to cause patient dissatisfaction with multifocal lenses. ${ }^{9,12}$

IOLs with a decreased near addition (add) dioptric power have been suggested as a potential remedy for these unsatisfactory PROs. The AcrySof IQ ReSTOR $+2.5 \mathrm{D}$ multifocal lens has been designed to allow better uncorrected intermediate vision and reduce glare and halos compared with previous, higher-add models. ${ }^{11,14-20}$ This lens was designed for patients who want to participate in activities requiring more intermediate $(53 \mathrm{~cm} / 21$ in) and distance $(4 \mathrm{~m} / 13 \mathrm{ft})$ vision, ${ }^{21}$ and the lens is intended to result in a lower incidence of glare because the central optic is designed for distance. A similar lens, the AcrySof IQ ReSTOR +3.0 D was designed for patients who desire a broad range of vision from 16 inches $(40 \mathrm{~cm})$ to distance. $^{22}$ In a 6-month postoperative survey of AcrySof IQ ReSTOR +3.0 D recipients, most reported "none/mild" difficulty with night vision, including glare and halos, but $13-14 \%$ of patients reported "severe" glare/flare, night vision issues, or halo). ${ }^{21}$

To date, patient-reported satisfaction beyond glare/halo has not been described after implantation with either the ReSTOR +2.5 D or the ReSTOR +3.0 D when implanted bilaterally or in blended vision, in which the ReSTOR $+2.5 \mathrm{D}$ would be implanted in the dominant eye. This study was designed to assess whether satisfaction rates in PROs would be higher with bilateral or blended implantation of these two lenses. Secondary outcomes included the refractive accuracy and the incidence of glare and halos.

\section{Materials and Methods}

This study was a prospective analysis of PROs and satisfaction among patients undergoing cataract surgery who had been implanted between 2 and 24 months previously with AcrySof IQ ReSTOR multifocal IOLs in both eyes. This study was conducted under the supervision of Aspire IRB (Santee, California) under protocol ID ALC-37193973 following the guidelines of the Declaration of Helsinki and with participants consenting to enroll with a verbal consent process through a scripted in person or telephonic interview. The "2.5 mini-monovision" group was implanted with the AcrySof IQ ReSTOR ActiveFocus +2.5 D or AcrySof IQ ReSTOR ActiveFocus $+2.5 \mathrm{D}$ add toric implant bilaterally, with the dominant eye targeted for emmetropia and the nondominant eye targeted for -0.5 sphere. The "2.5/3.0" group was implanted with the AcrySof IQ ReSTOR ActiveFocus $+2.5 \mathrm{D}$ add implant in the dominant eye and the AcrySof IQ ReSTOR +3.0 D add multifocal lens the nondominant eye. The "3.0/3.0" group was implanted bilaterally with the AcrySof IQ ReSTOR +3.0 D add multifocal IOL, targeting emmetropia. Data collection for the 3.0/3.0 group had been completed several months previously as part of another study but was identical in all aspects to the selection criteria and questionnaire methodology of the other two groups.

All eyes underwent phacoemulsification cataract surgery using either a manual or a femtosecond laser-assisted technique, with a target refraction as close to plano as the available lens powers allowed, erring on the side of the first myopic lens choice when necessary. The nondominant eye of patients in the 2.5 mini-monovision group underwent either manual or femtosecond laser-assisted phacoemulsification but had a prespecified target refraction, as mentioned previously.

Each of the authors' clinics establishes ocular dominance by having subjects hold a small aperture at arm's length while fixating on a distance visual target. Bringing the aperture closer to the eye, the examiners determined their preferred (dominant) eye.

Patients were excluded if they had significant ocular pathology that could alter their perception of the outcome of surgery, or if they had more than grade 1 posterior capsule opacity (PCO). All aspects of this study were conducted under the surveillance of Aspire Institutional Review Board (Santee, CA, USA) following the principles of the Declaration of Helsinki. Patients were asked to complete an electronic questionnaire, assisted by a research staff member if necessary, that evaluated their satisfaction with the surgery 
and with their spectacle independence. (See supplemental information for the questionnaire) Objective outcomes included final refraction, bilateral best-corrected visual acuity (BCVA) on a Snellen chart across all distances, and presence of PCO (if any).

\section{PRO Questionnaire}

This PRO questionnaire (MDBackline, Laguna Beach, CA, USA) was specifically developed and validated by covariance analysis in multiple studies that evaluated the satisfaction, spectacle independence, and effect of unwanted visual phenomena of patients who have undergone cataract surgery with presbyopia-correcting lenses. The assessment and validation of these subjective outcomes differentiate this questionnaire from the National Eye Institute Visual Function Questionnaire-14 (VF-14 QOL) and other general-use visual function questionnaires. This questionnaire has been in routine use in the authors' practices (and in other U.S.-based cataract practices) since 2014; results generated from this questionnaire have been used in other studies as well. ${ }^{23,24}$

As noted above, patients had been implanted between 2 and 24 months previously before being asked to complete the questionnaire. In this study, patients were contacted between 2 and 24 months following uncomplicated, bilateral cataract surgery with the specified lenses to complete the questionnaire instrument by each of the authors' clinic staff.

\section{Results}

\section{Demographics}

A total of 349 patients were recruited. Of these, 269 patients satisfied the inclusion and exclusion criteria and were enrolled in this study, with 102 patients in the 2.5 minimonovision group, 89 patients in the $2.5 / 3.0$ group, and 78 patients in the 3.0/3.0 group. Mean age was $71 \pm 8.1$ years (range 35-91 years) in the 2.5 mini-monovision group, 72.1 \pm 7.6 years (range $52-99$ years) in the 2.5/3.0 group, and 74.1 \pm 6.7 years (range 58-89 years) in the 3.0/3.0 group; these differences were not statistically significant $(P=0.77)$.

The mean time from the latest surgery to the date of the evaluation was also similar between groups: $4.2 \pm 2.6$ months (range 2-14 months) in the 2.5 mini-monovision group, $3.9 \pm 3.5$ months (range $2-10$ months) in the $2.5 / 3.0$ group, and 3.6 \pm 3.3 months (range 2-24 months) in the 3.0/ 3.0 group. Femtosecond laser-assisted cataract surgery was performed in 57 patients $(56 \%)$ in the 2.5 mini-monovision group and 18 patients $(22 \%)$ in the $2.5 / 3.0$ group. No patients in the 3.0/3.0 group had femtosecond laser surgery.

\section{Patient Satisfaction}

No statistically significant differences were noted in overall satisfaction among the groups, with "very satisfied" being reported in $74.5 \%$ of the 2.5 mini-monovision group, $74.1 \%$ of the 2.5/3.0 group, and $73.0 \%$ of the 3.0/3.0 group (Figure 1, $P<0.67$, Mann-Whitney $U$-test). Most patients responded they would be "very likely" to choose the same lenses again: $78 \%$ in the 2.5 mini-monovision group, $60 \%$ in the $2.5 / 3.0$ group, and $62 \%$ in the $3.0 / 3.0$ group $(P<0.58$, Mann-Whitney $U$-test). Most patients responded they were "very likely" or "somewhat likely" to refer friends and family for the same procedure: $96 \%$ of the 2.5 mini-monovision group, $88 \%$ of the $2.5 / 3.0$ group, and $85 \%$ of the $3.0 / 3.0$ group $(P<0.62)$. Conversely, four patients $(4 \%)$ in the 2.5 mini-monovision group, 4 patients $(4 \%)$ in the $2.5 / 3.0$ group, and two patients (3\%) in the 3.0/3.0 group reported they were either "very" or "somewhat" dissatisfied with their vision. Qualitative analysis of free-text responses from patients who reported dissatisfaction showed that dissatisfaction was generally related to the need for reading glasses in the 2.5 minimonovision group and with unwanted visual phenomena (glare/halos) in the $2.5 / 3.0$ and the $3.0 / 3.0$ groups, with

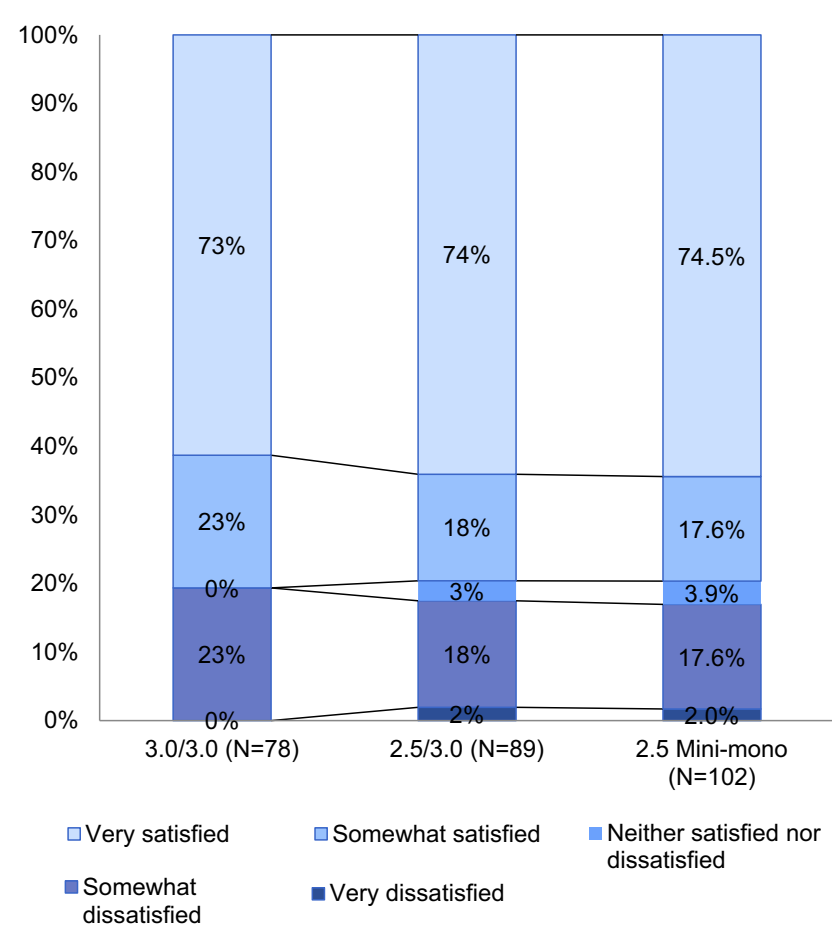

Figure I Overall patient satisfaction. No differences were statistically significant $(P<0.67$ for very satisfied, Mann-Whitney $U$-test). 
some patients describing ocular surface discomfort or other complaints not related to the implant choice itself.

\section{Spectacle Independence}

Overall spectacle independence (all activities combined) was similar among the groups, with some notable differences. The 2.5 mini-monovision group had significantly fewer patients reporting needing glasses "frequently or always," (11\%), compared with $34 \%$ in the $2.5 / 3.0$ group and $29 \%$ in the 3.0/3.0 group (chi-square test $P<0.002$ vs 3.0/3.0 and $P<0.0001$ vs $2.5 / 3.0$ ). Also, significantly more patients in the 2.5 mini-monovision group reported a need for glasses "sometimes or rarely" (53\%) compared with $35 \%$ in the 2.5/3.0 group and $36 \%$ in the 3.0/3.0 group (Figure 2, chisquare test $P<0.02$ vs $3.0 / 3.0$ and $P<0.01$ vs $2.5 / 3.0$ ). Other differences were not statistically significant.

When spectacle independence was separated by activity, a significant difference was found in the need for spectacles for intermediate vision (computer use), with none of the patients in the 2.5 mini-monovision group needing spectacles, compared with 18 patients $(20 \%)$ in the $2.5 / 3.0$ group and 27 patients $(35 \%)$ in the $3.0 / 3.0$ group (Figure $3, P<0.0001$ by chi-square test for between-group comparison). No other statistically significant differences were noted in spectacle independence by activity between the groups. One patient in the 2.5 mini-monovision group did not provide responses to overall spectacle independence and two did not provide responses to spectacle independence by activity. If all patients in that group had responded, the $P$-values would not have changed.

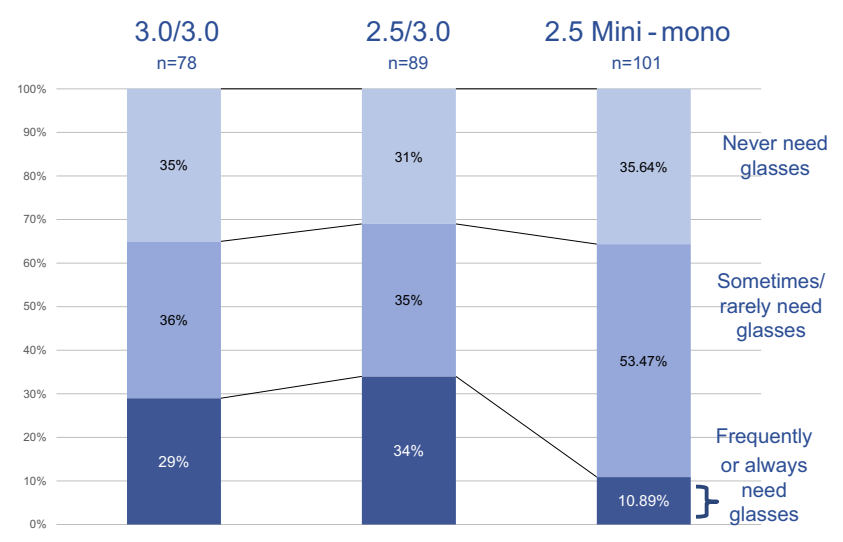

Figure 2 Overall spectacle independence (all activities). Patients with 2.5 minimonovision were significantly more likely to need glasses "sometimes/never" instead of "frequently/always" compared with patients in the 2.5/3.0 and 3.0/3.0 groups $(P<0.03$, chi-square test).

\section{Glare and Halos}

Patients in the 3.0/3.0 group reported significantly more glare and halos around lights in mesopic situations than patients in the other groups (Figure 4). These differences were statistically significant $(P<0.0001$, chi-square test for "extremely bothersome"). Glare/halo symptoms were rated as "extremely" bothersome by one patient (1\%) in the 2.5 mini-monovision group, by three patients $(3 \%)$ in the $2.5 / 3.0$ group, and by nine patients $(12 \%)$ in the $3.0 / 3.0$ group. Fifty-six percent $(56 \%)$ of patients in the 3.0/3.0 group labeled glare and halo as bothersome "a fair amount," "very much," or "extremely" compared with $29 \%$ in the $2.5 / 3.0$ group and $26 \%$ in the 2.5 mini-monovision group. These differences were statistically significant $(P<0.0001$, chi-square test $)$.

\section{Refractive Accuracy and BCVA}

Refractive accuracy was available in $94(92 \%)$ of patients in the 2.5 mini-monovision group, 72 (81\%) in the 2.5/3.0 group, and all $78(100 \%)$ in the $3.0 / 3.0$ group. Refractive accuracy was similar in all three groups at 1 month; 74 (79\%) patients in the 2.5 mini-monovision group, 46 (64\%) patients in the $2.5 /$ 3.0 group, and 55 patients $(71 \%)$ in the $3.0 / 3.0$ group were within $0.5 \mathrm{D}$ of the refractive target spherical equivalent. These differences were significantly different between the 2.5 mini-monovision and $2.5 / 3.0$ groups $(P<0.05$, Student's $t$-test). Other differences, including being within $1.0 \mathrm{D}$ of the refractive target spherical equivalent, were not statistically different at 1 month, as more than $90 \%$ in all groups reached that target: $93(99 \%)$ patients in the 2.5 mini-monovision group, 67 (93\%) patients in the 2.5/3.0 group, and 73 (94\%) patients in the 3.0/3.0 group ( $P>0.46$, Student's $t$-test).

BCVA at 1 month was similar between groups and not statistically significant (Figure 5). BCVA of 20/40 or better was achieved in all patients with available data in all three groups.

Subgroup analysis of patients who underwent femtosecond laser-assisted cataract surgery versus manual phacoemulsification did not reveal any statistically significant differences for any of the outcome measures reported above.

\section{Discussion}

This study evaluated patients implanted bilaterally with multifocal lenses to determine the patient-reported satisfaction and outcomes. Glare and halo are well-reported common and bothersome adverse effects of cataract surgery, ${ }^{13,25,26}$ are much more likely to occur with multifocal lenses than with monofocal lenses, ${ }^{26}$ and are leading causes of patient-reported dissatisfaction in the postoperative period. (Another cause is 


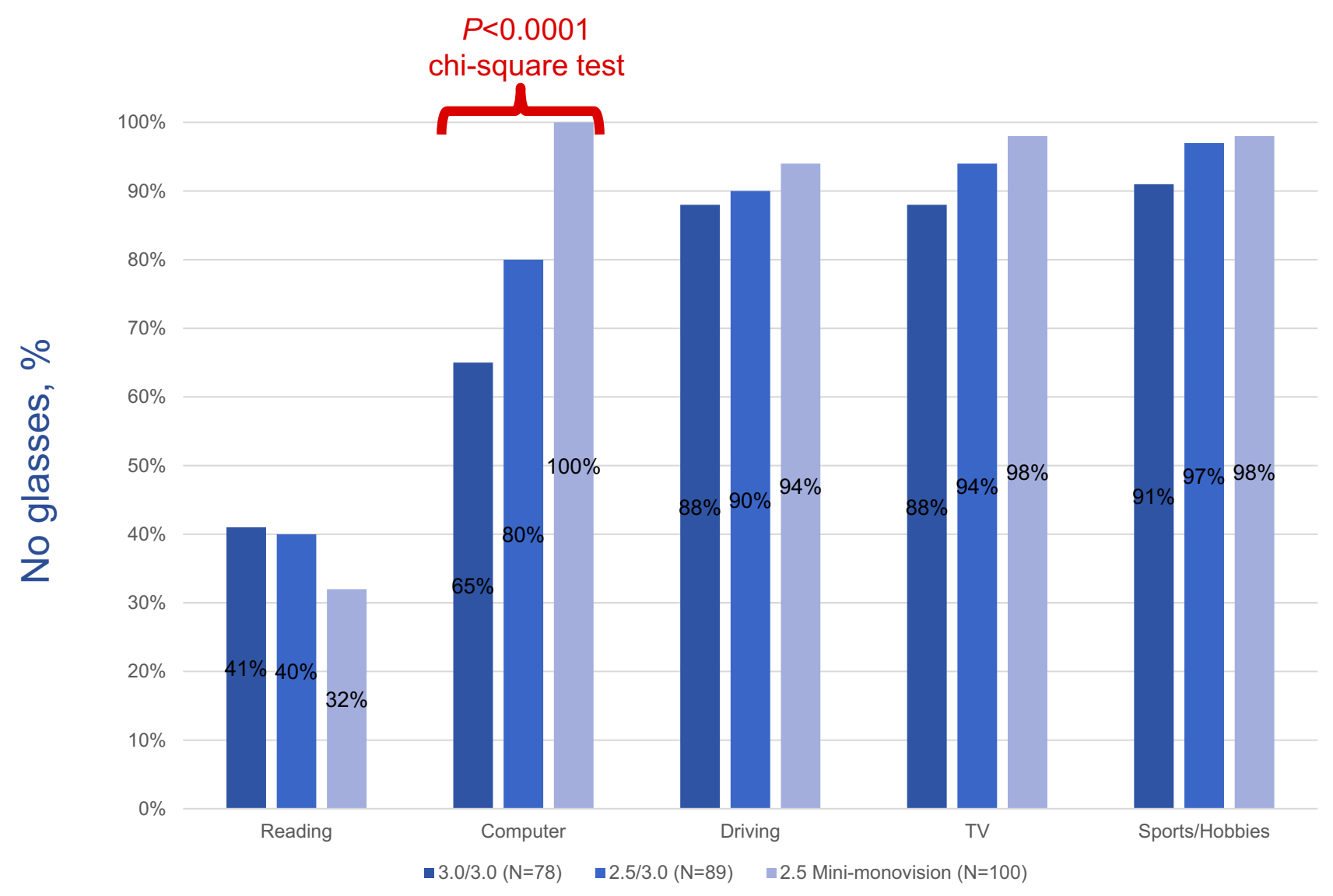

Figure 3 Spectacle independence by activity. Patients in the 2.5 mini-monovision group had significantly greater independence from glasses for computer use $(P<0.000$ I, chisquare test) but a greater need for reading glasses, although this difference was not significant (chi-square test).

postoperative need for spectacles for intermediate and/or near tasks. ${ }^{4}$ ) Since the introduction of multifocal IOLs, technology improvements have substantially reduced these adverse effects, but moderate glare has still been reported in about $21 \%$ of patients implanted with earlier iterations of the ReSTOR lenses. ${ }^{26}$

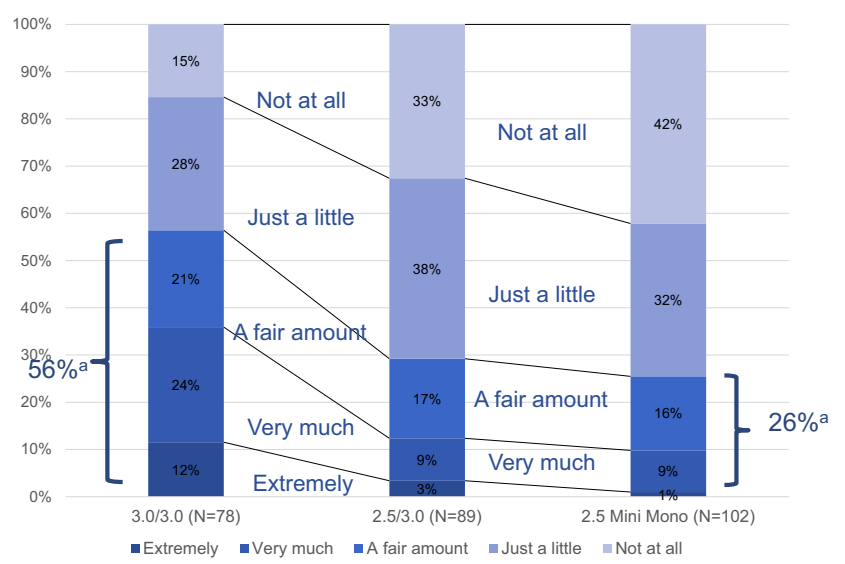

Figure 4 Glare and halos. Glare and halos were significantly less frequent and severe in patients in the 2.5/3.0 and 2.5 mini-monovision groups, compared with the $3.0 / 3.0$ group $\left({ }^{\mathrm{a}} P<0.000 \mathrm{I}\right.$, chi-square test).
This study provides a comparison of PROs between a group of patients implanted with two newer multifocal IOLs with different near adds $(+2.5 \mathrm{D}$ and $+3.0 \mathrm{D})$ and a group of patients implanted bilaterally with one of those lenses $(+3.0 \mathrm{D})$ who answered a patient questionnaire. We found the combination group had generally similar satisfaction and outcomes than the bilaterally implanted group, but significant differences were found for spectacle independence during computer use that favored the 2.5 minimonovision group.

Our results are similar to other studies; Vingolo et al found better near vision was reported after bilateral ReSTOR +3.0 D than ReSTOR +2.5 D, but both groups reported overall good performance. ${ }^{27}$ Shah et al reported patients who received either a toric or non-toric ReSTOR lens had significantly higher rates of improved uncorrected near and distance VA, and much higher scores for spectacle independence, than those implanted with a monofocal lens. ${ }^{4}$

The concept of blended vision is not novel; when multifocal lenses were first introduced, cataract surgeons reported on the technique as a means of achieving their 
desired visual outcomes. ${ }^{28-31}$ However, little has been written about the technique with newer multifocal IOLs. Bilbao-Calabuig et $\mathrm{al}^{29}$ investigated the visual outcomes between blended vision with the ReSTOR $+2.5 \mathrm{D}$ and +3.0 $\mathrm{D}$ compared with the bilateral implantation of a trifocal. That study concentrated on objective visual outcomes rather than patient-reported satisfaction survey results. Others have reported on objective visual outcomes with the ReSTOR +3.0 D and found better intermediate vision than higher-add lenses without losing distance or near

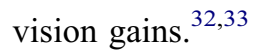

More recently, Nuijts et $\mathrm{al}^{34}$ reported on bilateral implantation with the ReSTOR $+2.5 \mathrm{D}$ and the combination of the ReSTOR $+2.5 \mathrm{D}$ in the dominant eye and the ReSTOR +3.0 D in the nondominant eye. They concentrated on clinical visual outcomes, finding the bilateral group had similar distance and intermediate vision, but the mixed group had better near distance. ${ }^{34}$

Our study is the first to document patient-reported satisfaction and refractive outcomes using blended ReSTOR +2.5 D and ReSTOR +3.0 D compared with bilateral implantation with ReSTOR +3.0 D or ReSTOR $+2.5 \mathrm{D}$ mini-monovision. Although refractive accuracy was comparable among the groups, PROs were greater in the +2.5 mini-monovision group, including sometimes/ rarely needing spectacles. In our study, none of the patients in the 2.5 mini-monovision group needed reading glasses for intermediate vision (ie, computer viewing), compared with $20 \%$ in the $2.5 / 3.0$ group and $35 \%$ of the 3.0/3.0 group who needed spectacles to view a computer. Our results support the findings of others on intermediate vision. Pedrotti et $\mathrm{al}^{35}$ reported on bilateral implantation of the ReSTOR +2.5 D and ReSTOR +3.0 D and found ReSTOR $+2.5 \mathrm{D}$ had better intermediate vision and better quality of vision than ReSTOR +3.0 D.

Further, the published defocus curves for these two lenses $^{21,22}$ suggest that mixed implantation would have complementary effects on the range of uncorrected vision; the defocus zone of poorest Snellen acuity with the ReSTOR +3.0 D - between -1.00 and -2.00 D of defocus - corresponds to the zone of best Snellen acuity with the $\operatorname{ReSTOR}+2.5 \mathrm{D}$ lens.

Our results seem to support those findings, in that our combination group also reported better quality of vision with less glare and halos than the bilaterally implanted ReSTOR +3.0 D group. However, our 2.5 mini-monovision group had the least bothersome glare and halo.

There are some possible explanations for the difference in patient-reported satisfaction and outcomes. First, the ReSTOR +2.5 D has a central optic that is focused for

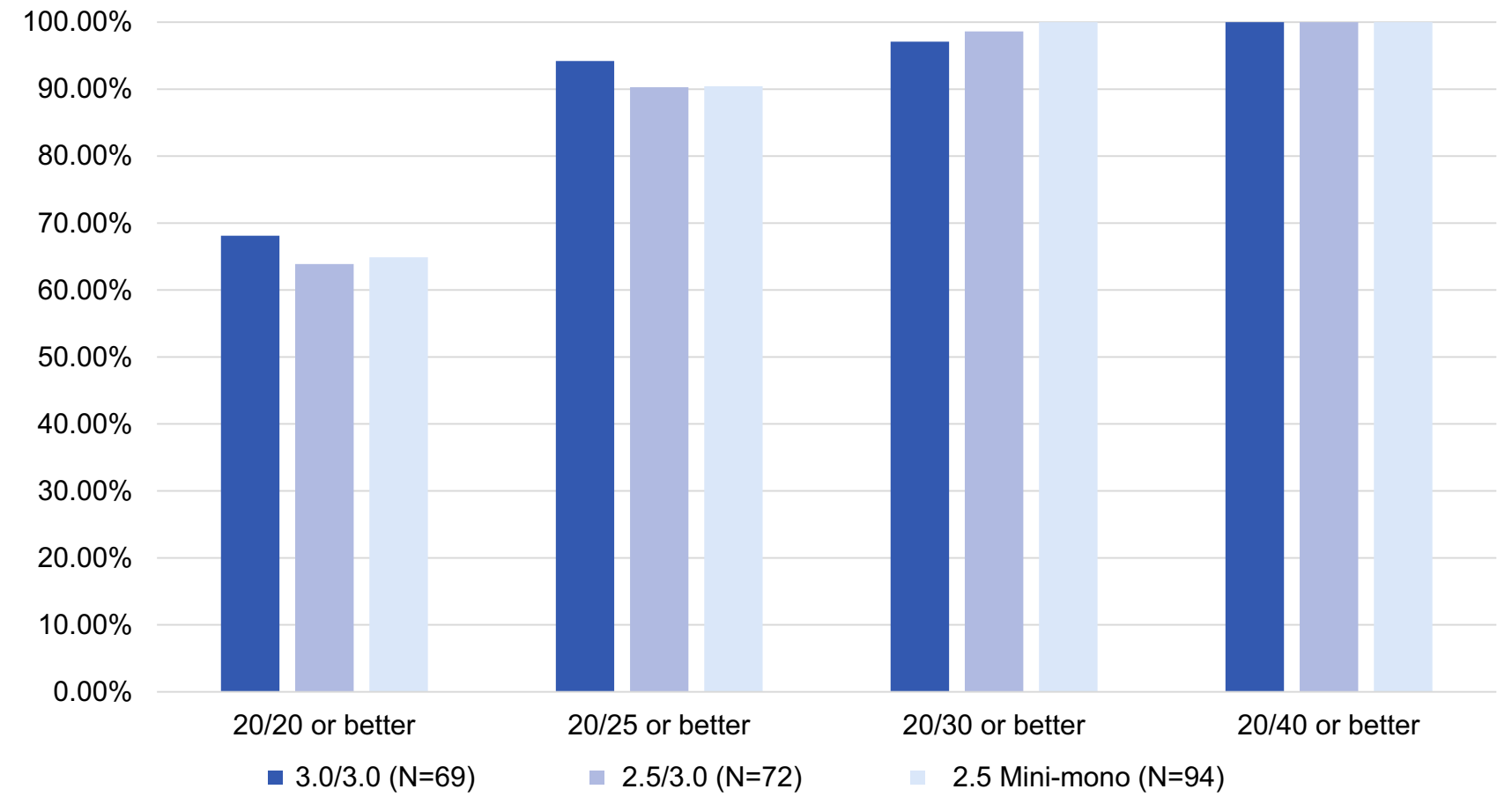

Figure 5 BCVA at I month. No differences were statistically significant ( $P>0.05$, chi-square test). Abbreviation: BCVA, best-corrected visual acuity. 
distance, which differentiates the lens from other multifocal IOLs. The lens design may possible have provided for fewer unwanted adverse effects when implanted in the dominant eye, as evidenced from our 2.5 mini-monovision group results. In our blended vision group, however, it is unclear if the same results would be achieved if the ReSTOR +2.5 D had been placed in the nondominant eye while the ReSTOR $+3.0 \mathrm{D}$ was placed in the dominant eye.

Trifocal lenses currently available in Europe should soon be available in the United States. Their presence may shift surgeons from mixing current multifocal IOLs toward bilateral trifocal implantation. However, many surgeons will adopt these new technologies slowly and will use the lenses described in this study in the meantime. The subjective results from this study may also serve as a useful baseline for comparison of subjective results from new implants.

This study does have some limitations. Although statistical significance was reached in PROs when differences were found between the groups, our sample size was small. To the authors' knowledge no other validated questionnaire is available that evaluates postoperative unwanted visual phenomena as well as spectacle independence and satisfaction in a post-cataract population. We did not query patients on dry eye, which may affect PROs. We would expect with similar age populations and a larger sample size that those confounding factors would be comparable between groups. Similarly, any patient who presented with PCO of more than grade 1 was excluded from this study, which eliminated high PCO as a confounder. Therefore, our results may not necessarily be extrapolated to a greater population.

These limitations are more than offset by the advantages of the study findings. This study is the first to compare PROs in a "mix-and-match" surgical approach of the same lens (with different adds) to a bilateral approach with each of the same lens adds. With the goal of ensuring patients are highly satisfied after premium lens implantation, our results may help other surgeons in their IOL planning.

\section{Conclusion}

For patients undergoing either mini-monovision or combined IOL implantation with the ReSTOR +2.5 mini-monovision and ReSTOR $+2.5 / 3.0$, overall PROs are similar to patients undergoing ReSTOR 3.0/3.0 bilateral surgery and favor mini-monovision for intermediate vision.

\section{Acknowledgments}

MDBackline LLC funded this study. Michelle Dalton, ELS, provided medical writing assistance; this assistance was funded by MDBackline, LLC.

\section{Disclosure}

This was an investigator-sponsored trial, supported by MDBackline, LLC, in collaboration with Alcon Laboratories. At the time of this study, all authors were in private practice; SSL is now the Chief Medical Officer at Alcon. At the time of this study, SSL and JAH were consultants to Alcon. JAH reports grants from Alcon, during the conduct of the study; personal fees from Alcon, outside the submitted work. MJ reports personal fees from Alcon, outside the submitted work. QA reports research support/funding from Alcon, during the conduct of the study. He is also the consultant and part of the Speaker's Bureau for Alcon and Bausch \& Lomb. The authors report no other conflicts of interest in this work.

\section{References}

1. Ianchulev T, Litoff D, Ellinger D, Stiverson K, Packer M. Office-based cataract surgery: population health outcomes study of more than 21 000 cases in the United States. Ophthalmology. 2016;123(4):723-728. doi:10.1016/j.ophtha.2015.12.020

2. American Academy of Ophthalmology Cataract and Anterior Segment Panel. Preferred Practice Pattern Guidelines: Cataract in the Adult Eye. San Francisco, CA: American Academy of Ophthalmology; 2011.

3. Brown GC, Brown MM, Menezes A, Busbee BG, Lieske HB, Lieske PA. Cataract surgery cost utility revisited in 2012: a new economic paradigm. Ophthalmology. 2013;120(12):2367-2376. doi:10.1016/j. ophtha.2013.04.030

4. Shah S, Peris-Martinez C, Reinhard T, Vinciguerra P. Visual outcomes after cataract surgery: multifocal versus monofocal intraocular lenses. $J$ Refract Surg. 2015;31(10):658-666. doi:10.3928/1081597 X-20150611-01

5. Sachdev GS, Sachdev M. Optimizing outcomes with multifocal intraocular lenses. Indian $J$ Ophthalmol. 2017;65(12):1294-1300. doi:10.4103/ijo.IJO_1072_17

6. Hu JQ, Sarkar R, Sella R, Murphy JD, Afshari NA. Cost-effectiveness analysis of multifocal intraocular lenses compared to monofocal intraocular lenses in cataract surgery. Am J Ophthalmol. 2019; S00029394(19)30125-4. doi:10.1016/j.ajo.2019.03.019

7. Cochener B, Lafuma A, Khoshnood B, Courouve L, Berdeaux G. Comparison of outcomes with multifocal intraocular lenses: a meta-analysis. Clin Ophthalmol. 2011;5:45-56. doi:10.2147/ OPTH.S14325

8. Cao K, Friedman DS, Jin S, et al. Multifocal versus monofocal intraocular lenses for age-related cataract patients: a system review and meta-analysis based on randomized controlled trials. Surv Ophthalmol. 2019; S0039-6257(18)30165-6. doi:10.1016/j. survophthal.2019.02.012 
9. Javitt JC, Steinert RF. Cataract extraction with multifocal intraocular lens implantation: a multinational clinical trial evaluating clinical, functional, and quality-of-life outcomes. Ophthalmology. 2000;107 (11):2040-2048. doi:10.1016/S0161-6420(00)00368-7

10. Javitt JC, Wang F, Trentacost DJ, Rowe M, Tarantino N. Outcomes of cataract extraction with multifocal intraocular lens implantation: functional status and quality of life. Ophthalmology. 1997;104 (4):589-599. doi:10.1016/S0161-6420(97)30265-6

11. Vingolo EM, Grenga P, Iacobelli L, Grenga R. Visual acuity and contrast sensitivity: AcrySof ReSTOR apodized diffractive versus AcrySof SA60AT monofocal intraocular lenses. J Cataract Refract Surg. 2007;33(7):1244-1247. doi:10.1016/j.jcrs.2007.03.052

12. Woodward MA, Randleman JB, Stulting RD. Dissatisfaction after multifocal intraocular lens implantation. J Cataract Refract Surg. 2009;35(6):992-997. doi:10.1016/j.jcrs.2009.01.031

13. de Silva SR, Evans JR, Kirthi V, Ziaei M, Leyland M. Multifocal versus monofocal intraocular lenses after cataract extraction. Cochrane Database Syst Rev. 2016;12:CD003169. doi:10.1002/ 14651858.CD003091.pub4

14. Alfonso JF, Madrid-Costa D, Poo-López A, Montés-Micó R. Visual quality after diffractive intraocular lens implantation in eyes with previous myopic laser in situ keratomileusis. J Cataract Refract Surg. 2008;34(11):1848-1854. doi:10.1016/j.jcrs.2008.07.023

15. Chaves MA, Hida WT, Tzeliks PF, et al. Comparative study on optical performance and visual outcomes between two diffractive multifocal lenses: AMO Tecnis ${ }^{\circledR}$ ZMB00 and AcrySof ${ }^{\circledR}$ IQ ReSTOR $^{\circledR}$ multifocal IOL SN6AD1. Arq Bras Oftalmol. 2016;79 (3):171-176. doi:10.5935/0004-2749.20160050

16. Chiam PJ, Chan JH, Haider SI, Karia N, Kasaby H, Aggarwal RK. Functional vision with bilateral ReZoom and ReSTOR intraocular lenses 6 months after cataract surgery. J Cataract Refract Surg. 2007;33(12):2057-2061. doi:10.1016/j.jcrs.2007.07.029

17. Cochener B, Fernández-Vega L, Alfonso JF, Maurel F, Meunier J, Berdeaux G. Spectacle independence and subjective satisfaction of ReSTOR multifocal intraocular lens after cataract or presbyopia surgery in two European countries. Clin Ophthalmol. 2010;4:81-89. doi:10.2147/opth.s9403

18. Gierek-Ciaciura S, Cwalina L, Bednarski L, Mrukwa-Kominek E. A comparative clinical study of the visual results between three types of multifocal lenses. Graefes Arch Clin Exp Ophthalmol. 2010;248 (1):133-140. doi:10.1007/s00417-009-1177-4

19. Souza CE, Muccioli C, Soriano ES, et al. Visual performance of AcrySof ReSTOR apodized diffractive IOL: a prospective comparative trial. Am J Ophthalmol. 2006;141(5):827-832. doi:10.1016/j. ajo.2005.12.031

20. Wang Q, Zhao G, Wang Q, Jia W. Visual quality after AcrySof IQ ReSTOR intraocular lens implantation in eyes with high myopia. Eur J Ophthalmol. 2012;22(2):168-174. doi:10.5301/EJO.2011.8357

21. AcrySof ${ }^{\circledR} I Q$ ReSTOR ${ }^{\circledR}+2.5$ D IOL [Package Insert]. Fort Worth, TX: Alcon; 2016.
22. AcrySof ${ }^{\circledR} I Q$ ReSTOR ${ }^{\circledR}+3.0$ D IOL [Package Insert]. Fort Worth, TX: Alcon; 2016.

23. Hovanesian JA. Patient-reported outcomes of multifocal and accommodating intraocular lenses: analysis of 117 patients 2-10 years after surgery. Clin Ophthalmol. 2018;12:2297-2304. doi:10.2147/OPTH. S182943

24. Hovanesian J What factors drive the highest patient-reported satisfaction with multifocal IOLs. Presented as Paper \# 11947 at: ASCRS•ASOA Symposium \& Congress; April 17-21; 2015; San Diego, CA.

25. Buckhurst PJ, Naroo SA, Davies LN, Shah S, Drew T, Wolffsohn JS. Assessment of dysphotopsia in pseudophakic subjects with multifocal intraocular lenses. BMJ Open Ophthalmol. 2017;1(1):e000064. doi:10.1136/bmjophth-2016-000064

26. Leyland M, Pringle E. Multifocal versus monofocal intraocular lenses after cataract extraction. Cochrane Database Syst Rev. 2006;4:CD003169.

27. Vingolo EM, Carnevale C, Fragiotta S, Rigoni E, Iacobelli L. Visual outcomes and contrast sensitivity after bilateral implantation of multifocal intraocular lenses with +2.50 or +3.0 diopter addition: 12 month follow-up. Semin Ophthalmol. 2017;32(5):588-592. doi:10.3109/08820538.2015.1131839

28. Goes FJ. Visual results following implantation of a refractive multifocal IOL in one eye and a diffractive multifocal IOL in the contralateral eye. $J$ Refract Surg. 2008;24(3):300-305. doi:10.3928/1081597X-20080301-13

29. Bilbao-Calabuig R, González-López F, Amparo F, Alvarez G, Patel SR, Llovet-Osuna F. Comparison between mix-and-match implantation of bifocal intraocular lenses and bilateral implantation of trifocal intraocular lenses. J Refract Surg. 2016;32(10):659-663. doi:10.3928/1081597X20160630-01

30. Gunenc U, Celik L. Long-term experience with mixing and matching refractive array and diffractive CeeOn multifocal intraocular lenses. $J$ Refract Surg. 2008;24(3):233-242. doi:10.3928/1081597X-20080301-04

31. Yoon SY, Song IS, Kim JY, Kim MJ, Tchah H. Bilateral mix-andmatch versus unilateral multifocal intraocular lens implantation: long-term comparison. J Cataract Refract Surg. 2013;39(11):16821690. doi:10.1016/j.jcrs.2013.04.043

32. Santhiago MR, Wilson SE, Netto MV, et al. Visual performance of an apodized diffractive multifocal intraocular lens with +3.00 -d addition: 1-year follow-up. J Refract Surg. 2011;27(12):899-906. doi:10.3928/1081597X-20110816-01

33. Kohnen T, Nuijts R, Levy P, Haefliger E, Alfonso JF. Visual function after bilateral implantation of apodized diffractive aspheric multifocal intraocular lenses with a $+3.0 \mathrm{D}$ addition. $J$ Cataract Refract Surg. 2009;35(12):2062-2069. doi:10.1016/j.jcrs.2009.08.013

34. Nuijts RMMA, Jonker SMR, Kaufer RA, et al. Bilateral implantation of $+2.5 \mathrm{D}$ multifocal intraocular lens and contralateral implantation of +2.5 $\mathrm{D}$ and +3.0 D multifocal intraocular lenses: clinical outcomes. $J$ Cataract Refract Surg. 2016;42(2):194-202. doi:10.1016/j.jcrs.2016.02.009

35. Pedrotti E, Carones F, Aiello F, et al. Comparative analysis of visual outcomes with 4 intraocular lenses: monofocal, multifocal, and extended range of vision. J Cataract Refract Surg. 2018;44(2):156167. doi:10.1016/j.jcrs.2017.11.011
Clinical Ophthalmology

\section{Publish your work in this journal}

Clinical Ophthalmology is an international, peer-reviewed journal covering all subspecialties within ophthalmology. Key topics include: Optometry; Visual science; Pharmacology and drug therapy in eye diseases; Basic Sciences; Primary and Secondary eye care; Patient Safety and Quality of Care Improvements. This journal is indexed on PubMed
Central and CAS, and is the official journal of The Society of Clinical Ophthalmology (SCO). The manuscript management system is completely online and includes a very quick and fair peer-review system, which is all easy to use. Visit http://www.dovepress.com/ testimonials.php to read real quotes from published authors. 